\title{
ESTUDO DA EXPRESSÃO DA ENZIMA LIGNINA PEROXIDASE DE LENTINUS TIGRINUS E SUA CLONAGEM EM CÉLULAS DE E. COLI
}

\author{
Cleidineia Souza de Santana ${ }^{1}$; Raquel Guimarães Benevides²; Dalila de Souza Santos \\ Ferreira $^{3}$ \\ 1. Bolsista PIBIC - Af/CNPq, Graduando em Bacharelado em Ciências Biológicas, Universidade Estadual de Feira de \\ Santana, e-mail: s.santanacleide@yahoo.com.br \\ 2. Orientador, Departamento de Ciências Biológicas, Universidade Estadual de Feira de Santana, e-mail: \\ raquelgb@gmail.com \\ 3. Participante do projeto, Departamento de Ciências Biológicas, Universidade Estadual de Feira de Santana, e-mail: \\ dalilassouza@gmail.com
}

PALAVRAS CHAVES: fungo; resíduos agroindustriais; enzima

\section{INTRODUÇÃO}

O Brasil apresenta vantagens para o desenvolvimento de uma indústria baseada em matérias-primas renováveis devido à vasta biodiversidade existente em seu território, cultivos agrícolas em grande extensão, diversidade de clima, cujo bioprocessamento desperta grande interesse econômico e social (COUTINHO, BONTEMPO, 2010). Atualmente os resíduos agroindustriais vêm aumentando com o processo de industrialização. A utilização desses resíduos em bioprocessos como substrato alternativo pode solucionar problemas ambientais causados por sua disposição incorreta, além de agregar valor a eles. (PANDEY; SOCCOL; MITCHELL, 2000).

Uma grande variedade de fungos e bactérias consegue degradar esse material lignocelulósico usando uma bateria de enzinas hidrolíticas e oxidativas (VITTI, 1988). As enzimas ligninolíticas se destacam entre as oxidorredutases, atuando sobre seus substratos de forma difusa, não-específica, por vezes indireta e orientada basicamente pelas diferenças entre os potencias de oxidorredução dos substratos e enzimas e agem via mediadores não proteicos (ESPOSITO; AZEVEDO, 2004). O sistema ligninolítico básico é formado pelas enzimas denominadas fenoloxidases, onde estão a lacase e a tirosinase, e as peroxidases. As peroxidases, por sua vez, são constituídas pela peroxidase dependente de manganês $(\mathrm{MnP}) \mathrm{e}$ pela lignina peroxidase (LiP) (HATAKKA, 1994; HOFRICHTER, 2002).

Desse modo, o presente trabalho propõe avaliar a expressão da enzima Lignina peroxidase (LiP) do fungo Lentinus tigrinus e sua clonagem em células de E. coli objetivando-se uma futura aplicação na deslignificação no bagaço de cana.

\section{METODOLOGIA}

O fungo Lentinus tigrinus foi adquirida na Coleção de Cultura de Microrganismos da Bahia (CCMB) da UEFS, preservado em método Castellani. Para a reativação do fungo o micélio de Lentinus tigrinus foi transferido para meio de cultura sólido, Agar batata e dextrose (BDA) e posteriormente o micélio foi transferido para o meio de cultura semissólido, bagaço de cana e sulfato de amônia (BCSA), utilizando-se as seguintes concentrações ( $8 \mathrm{~g}$ de bagaço de cana e $2 \mathrm{~g}$ de sulfato de amônio) sendo incubado em B.O.D a $25^{\circ} \mathrm{C}$ por 7 dias, para induzir a produção da enzima de interesse.

No procedimento de extração de RNA, seguiu-se o protocolo do Reagente Trizol (Invitrogen $囚$ ). Para o processo de extração fez-se a remoção do fungo da placa de petri, transferindo-o para o cadinho e macerado em nitrogênio liquido, após o fungo ser totalmente macerado foi transferido para um microtubo de $2 \mathrm{~mL}$, em seguida adicionou-se $1 \mathrm{~mL}$ do reagente Trizol e foi homogeneizado em vórtex por aproximadamente 5 segundos; após homogeneizado a mistura foi incubada em gelo por 5 minutos. Decorridos os cinco minutos 
fez-se o procedimento para a separação das fases, adicionou-se $200 \mu \mathrm{L}$ de clorofórmio e em seguida agitou-se manualmente por 15 segundos, depois foi incubado por 3 minutos em gelo, seguindo-se, foi centrifugado a $12.000 \mathrm{xg}$, por 10 minutos a $4^{\circ} \mathrm{C}$. Depois de centrifugada houve a formação de 3 fases, sendo estas: clorofórmio-fenol, interfase e a fase aquosa, esta foi transferida para um novo microtubo. Após a separação das fases, fez-se o isolamento do RNA; nesse processo adicionou-se $500 \mu \mathrm{L}$ de isopropanol $100 \%$ à fase aquosa e em seguida foi incubado em gelo por 10 minutos, após isso centrifugou-se a $12.000 \mathrm{x} g$ por 10 minutos a $4^{\circ} \mathrm{C}$, prosseguindo-se, foi retirado o sobrenadante e o pellet foi lavado com $1 \mathrm{ml}$ de etanol $75 \%$, agitou-se em vórtex, em seguida centrifugou-se novamente a $7500 \mathrm{x} g$ por 5 minutos a $4^{\circ} \mathrm{C}$, descartou-se o sobrenadante e deixou-se o pellet secar por até 10 minutos.

Transcorridos esse tempo o RNA foi ressuspendido em $50 \mu \mathrm{L}$ de água RNAse-free, o RNA obtido foi armazenado em $-20^{\circ} \mathrm{C}$. O RNA extraído foi analisado quantitativamente pela técnica de espectofotometria, sendo também analisado por visualização em fotografia digital, após 1 hora de corrida eletroforética. Posteriormente foi feita a síntese de DNA complementar utilizando-se a enzima M-MLV Reverse, Transcriptase, seguindo-se as recomendações do fabricante.

Os primers para o gene da enzima em estudo Lignina peroxidase foram desenhados com base nas sequências nucleotídicas disponíveis no banco de dados NCBI - (National Center for Biotechnology Information) https://www.ncbi.nlm.nih.gov/nucleotide/. A verificação da estrutura do primer, porcentagem de conteúdo $\mathrm{C} / \mathrm{G}$, bem como temperatura de melting (Tm), foi feita utilizando o simulador gratuito de construção de primer disponível na página https://www.idtdna.com/calc/analyzer.

A amplificação do cDNA foi feita por meio da reação de polimerização em cadeia (PCR). Como fita molde foi utilizada a primeira fita de cDNA e como iniciadores, o primer para o gene (como senso) e oligo-dT (Ancor Primer, anti-senso). A reação foi feita utilizandose o kit Quiagen ${ }^{\circledR}$ Master Mix: enzima Top taq Master mix, iniciadores para o gene ( primers senso e anti-senso), DNA como molde e Agua Nucleasefree, as condições para a reação de PCR foi feita de acordo com as instrução do fabricante, seguindo-se as etapas da tabela 2.

Tabela 2 - Etapas referentes à reação de polimerase em cadeia

\begin{tabular}{llll}
\hline PASSO & $\begin{array}{l}\text { TEMPERATUR } \\
\text { A }\left({ }^{\circ} \mathbf{C}\right)\end{array}$ & TEMPO & $\mathbf{N}^{\circ}$ CICLOS \\
\hline $\begin{array}{l}\text { Desnaturação } \\
\text { Inicial }\end{array}$ & 94 & $3^{\prime}$ & 1 \\
Desnaturação & 94 & $45^{\prime}$, & 35 \\
Anelamento & 59 & $1^{\prime}$ & 35 \\
Extensão & 72 & $3^{\prime}$ & 35 \\
Extensão Final & 72 & $5^{\prime}$ & 1 \\
\hline
\end{tabular}

O produto obtido a partir da reação de PCR foi purificado utilizando-se o kit PureLink ${ }^{\circledR}$ Quick Gel Extraction - o procedimento foi feito seguindo as recomendações do fabricante.

\section{RESULTADOS E DISCUSSÃO}

Após o período de incubação do fungo em meio semissólido bagaço de cana e sulfato de amônia (BCSA), sob as condições favoráveis para o seu crescimento, o fungo apresentou um menor crescimento de massa micelial, comparado com o crescimento quando reativado em meio BDA, possivelmente em decorrência do meio ser relativamente pobre em nutrientes, mas foi considerado satisfatório para a análise da indução da enzima lignina peroxidase (LiP) quando submetido à extração de RNA total, onde foi possível verificar a integridade o RNA 
extraído, uma vez que as bandas referentes aos RNAr 28S e $18 \mathrm{~S}$ mostram-se detectáveis (Figura 1).

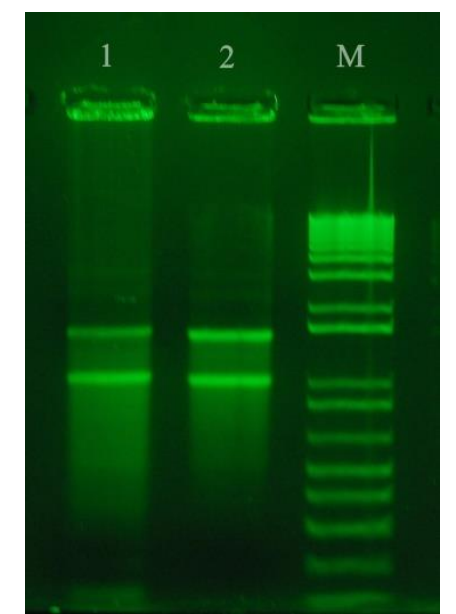

Figura 1: Gel de agarose 1,2\% com resultado de RNA, cultivado em BCSA. Da direita para a esquerda: M: Marcador de massa molecular de 1kb, plus DNA Ladder Invitrogen; 1 e 2: RNA de Lentinus tigrinus.

Tais características foram inicialmente exploradas pelo fato do meio (BCSA) apresentar uma elevada quantidade de materiais ligninocelulósicos e baixa quantidade de carboidratos livres, onde, de acordo com autores tais como, Menezes (2009) e Silva et al. (2014), resíduos agroindustriais a exemplo do bagaço de cana é um substrato com alta capacidade de induzir a produção de enzimas ligninolíticas pelos fungos basidiomicetos.

$\mathrm{O}$ resultado da amplificação relativa ao gene de LiP de Lentinus tigrinus, com o uso dos primers específicos desenhado (Tabela 2), após a reação de PCR, utilizando-se o cDNA obtido à partir da extração de RNA, foi verificado por eletroforese em gel de agarose $1 \%$ (Figura 2), onde foi possível constatar a amplificação do fragmento esperado de aproximadamente $650 \mathrm{pb}$. Houve a formação de fragmentos inespecíficos de tamanhos menores, o que levou à decisão de purificação do inserto desejado à partir de extração da banda em gel.

Tabela 2 - Dados referentes ao primer desenhado

\begin{tabular}{lccc} 
Denominação & Seqüiência $\left(\mathbf{5}^{\prime} \mathbf{3}^{\prime}\right)$ & $\begin{array}{c}\text { Teor de } \\
\text { C/G }\end{array}$ & Temp. de melting(Tm) \\
\hline LiP_1 & $\begin{array}{c}G G B \text { GGM GGT GGM GAC } \\
G G Y\end{array}$ & $71,5 \%$ & $68^{\circ} \mathrm{C}$ \\
LiP_2 & $\begin{array}{c}\text { ACT GCN TGY GAG TGG } \\
\text { CAG TCG TT }\end{array}$ & $56.2 \%$ & $65.6^{\circ} \mathrm{C}$ \\
\hline
\end{tabular}




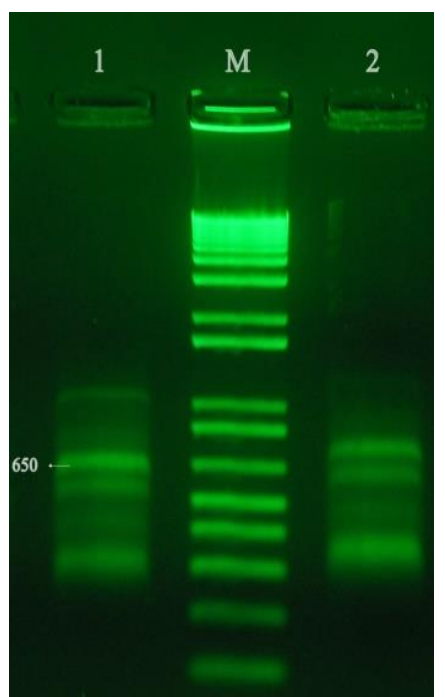

Figura 2: Gel de agarose 1,2\% com resultado do PCR a partir do cNDA de Lentinus tigrinus cultivado em meio BCSA. M: Marcador de massa molecular de 1kb, plus DNA Ladder Invitrogen - Invitrogen; 1 e 2:Amplificado referente à sequencia

O inserto purificado está sendo enviado para sequenciamento, e a partir do resultado obtido será possível desenhar primers que flanqueiem a sequência codificante completa de uma LiP de L. tigrinus, permitindo sua clonagem e produção recombinante em vetor de expressão.

\section{CONSIDERAÇÕES FINAIS}

De acordo com os resultados por meio da extração de RNA, conclui-se que o meio BCSA foi favorável para a expressão da enzima Lignina peroxidase pelo fungo Lentinus tigrinus. Conforme o resultado do produto de Lentinus tigrinus, após a reação de PCR a partir de cDNA, foi possível verificar o fragmento de aproximadamente $650 \mathrm{pb}$ referente à amplificação da região específica de LiP, confirmando que houve a indução da enzima, pretendendo-se como próximos passos cloná-la e expressá-la em células de E. coli.

\section{REFERÊNCIAS}

SILVA, M. L. C. et al. (2014). Production of manganese peroxidase by Trametes villosa on unexpensive substrate and its application in the removal of lignin from agricultural wastes. Advances in Bioscience and Biotechnology, v. 5, n. 14, p. 1067.

COUTINHO, P. L. A.; BOMTEMPO, J. V. (2010) Uso de roadmaps tecnológicos para favorecer o ambiente de inovação: uma proposta em matérias primas renovável. In: SIMPOI.

MENEZES, C. R.; SILVA, I. S.; DURRANT, L. R. (2009). Bagaço de cana: fonte de produção de enzimas lignocelulolíticas. Estudos tecnológicos vol. 5, nº 1. p. 68-78.

ESPOSITO, E; AZEVEDO, J. L. (2004). (org.) Fungos: uma introdução à biologia, bioquímica e biotecnologia. Caxias do Sul: Educs, , 510 p.

HOFRICHTER, M. (2002). Review: lignin conversion by manganese peroxidase (MnP). Enzyme Microbiol Technology, v. 30, p. $454-466$.

PANDEY, A ; SOCCOL , C. R ; MITCHELL, D. (2000). New developments in solid state fermentation: I-bioprocess and products. Process Biochemistry, London, v. 35, p. 1153-1169.

HATAKKA, A. (1994). Lignin - modifying enzyme from selected white - rot fungi: production and role in lignin degradation. FEMS Microbiology Review. .v. 13, p.125 - 135

VITTI, L. S. S. (1988). Condições de produção e atividade da celulose do fungo Aspergillus $s p$ e seus mutantes isolados de bagaço de cana. 1988. 108 p. Dissertação (Mestrado em Energia Nuclear na Agricultura) - Centro de Energia Nuclear na Agricultura, Universidade de são Paulo, Piracicaba. 